\title{
Smart Cities and Positive Energy Districts: Urban Perspectives in 2020
}

\author{
Paola Clerici Maestosi
}

Citation: Clerici Maestosi, P. Smart Cities and Positive Energy Districts: Urban Perspectives in 2020. Energies 2021, 14, 2351. https://doi.org/ $10.3390 /$ en14092351

Received: 26 December 2020

Accepted: 26 January 2021

Published: 21 April 2021

Publisher's Note: MDPI stays neutral with regard to jurisdictional claims in published maps and institutional affiliations.

Copyright: (C) 2021 by the author. Licensee MDPI, Basel, Switzerland. This article is an open access article distributed under the terms and conditions of the Creative Commons Attribution (CC BY) license (https:/ / creativecommons.org/licenses/by/ $4.0 /)$.
ENEA-Italian National Agency for New Technologies, Energy and Sustainable Economic Development, Department Energy Technologies and Renewables TERIN-SEN Smart Energy Networks, 40127 Bologna, Italy; paola.clerici@enea.it

\begin{abstract}
This Special Issue of Energies "Smart Cities and Positive Energy Districts: Urban Perspectives in 2020" introduce contemporary research on Smart Cities and on Positive Energy Districts. The topic highlights the variety of research within this field: from the analysis of 61 Positive Energy Districts cases to papers illustrating the Positive Energy Districts dimension or Smart Energy Communities supporting low carbon energy transition as well as selected Smart Cities Experiences. The focus is thus given on how RD\&I stakeholders and Municipalities are facing sustainable urban development challenges. An overview of Horizon Europe RD\&I program on sustainable urban areas is provided.
\end{abstract}

Keywords: Positive Energy District; sustainable urban areas; transition

\section{Introduction}

The United Nations Sustainable Development Goals (SDGs) are the global political agenda that addresses the most pressing social, economic and environmental challenges in an integrated way. The EU is committed to implementing the Sustainable Development Goals in all policies, including Research and Innovation (R\&I) with the aim of modernizing the European economy and society and thus achieving a sustainable future. The EU Framework Program for Research and Innovation is one of the main vehicles promoting the transition to a sustainable future with the aim of becoming the first climate-neutral continent by 2050. All H2020 investments concerned at least one of the 17 SDGs, channeling $84 \%$ of investments on these.

While knowing that all the SDGs are equally important to achieve the goal of a sustainable future and that pathways to sustainability varies greatly, SDG 11 Sustainable Cities and Communities was funded most of all in the H2020 Framework Program of EU R\&I with a relatively high share (43\% to $58 \%$ ) of total investment.

Thus, Europe capitalizes on over 30 years of investment in transnational EU Research and Innovation (R\&I) on sustainable development. Within this timeline urban areas have been engaged in a multitude of initiatives aimed to boost sustainability dimension at urban scale, upgrading urban infrastructure and services, with a view to creating better environmental, social and economic conditions and enhancing cities' attractiveness and competitiveness. Reflecting these developments new "categories of cities" have entered the policy discourse but what still stands is that Horizon 2020 invested $43 \%$ of its budget (EUR 19.5 billion) on SDG 11 Sustainable Cities and Communities, mainly supporting Smart Cities Paradigm. In coming Horizon Europe the broad conceptualization of sustainable urbanization will stimulate cities, urban areas, and neighborhoods with an effective Research Development and Innovation program promoting 100 Positive Energy Districts and 100 Climate Neutral Cities within 2025. In this framework a reflection on the past and future of urban sustainable development is important to figure out next steps to support urban transition at the best. Thus EERA Joint Program on Smart Cities, a dedicated re- 
search network with own research program on Smart Cities and Positive Energy District, supported a special issues serie:

1. 2018-European Pathways for the Smart Cities to come, DOI: 10.13128/Techne-2356;

2. 2019-Tools, technologies and system integration for the Smart and Sustainable Cities to come, DOI: $10.5278 /$ ijsepm. 3515

Knowing that Horizon Europe Framework Program will deeply innovate Research, Development and Innovation for sustainable urban areas, the Scientific Board for EERA Joint Program on Smart City Special Issues Series where the author of this editorial acts as Coordinator, outlined topics of interest for third special issue:

- Smart Cities experiences

- Smart Energy Communities supporting the low carbon energy transition

- Positive Energy District

Moreover, as several international activities on sustainable urbanization are ongoing, the aims of this third special issue is to provide a clear reference framework about Horizon Europe Funding to boost transition to sustainable urban areas, which is highlighted by perspective paper [1] by Paola Clerici Maestosi guest editor of this special issue and Maria Beatrice Andreucci and Paolo Civiero as co-authors.

\section{Published Papers Highlights}

This Editorial article provides a summary of the Special Issue of Energies, covering the published papers [1-9] which address several of the topics mentioned in the Introduction. Table 1 identifies the most relevant topics in each published paper.

Table 1. Topic covered each publication.

\begin{tabular}{|c|c|c|c|c|c|c|c|c|c|c|}
\hline \multirow{2}{*}{ Topic } & \multicolumn{10}{|c|}{ Publication } \\
\hline & [1] & [2] & [3] & [4] & [5] & [6] & [7] & [8] & [9] & TOT. \\
\hline Smart Cities experience & & $x$ & $x$ & & $x$ & & $x$ & & $x$ & 5 \\
\hline $\begin{array}{c}\text { Smart Energy } \\
\text { Communities } \\
\text { supporting low energy } \\
\text { transition }\end{array}$ & & $X$ & & & $x$ & $x$ & & & $x$ & 4 \\
\hline Positive Energy District & $X$ & & $X$ & $X$ & & $X$ & & $X$ & & 5 \\
\hline
\end{tabular}

As shown in Table 1, most of the publications focus on Positive Energy Districts (5) while some of these (2) include someway contents deriving from Smart Cities experiences. Then we have five papers on Smart Cities experience and among these, two reflect on the Positive Energy District topic. This is clear evidence that a strong link exists among these two approaches which are able to boost sustainable urban transition. Finally four papers focus on Smart Energy Communities supporting the low carbon energy transition.

The nine articles have been selected after a peer review process and we are thankful to all the (32) forty-two authors from several countries (in alphabetic order: Austria, Denmark, Italy, Netherland, Poland, and Portugal) for their contribution to the Special Issue.

In the work [1], Justyna Patalas-Maliszewska and Hanna Łosyk present the results of an analysis about a Sustainable Urban Development Card for Zielona Góra. This Polish city which, in 2019, had the largest fleet of electric buses represent the case study of the research based on the data received from the Municipal Department of Transport of Zielona Góra. According to the data the values of SDGs were calculated for electric busses and then compared with conventional diesel busses. Moreover, the results of a questionnaire highlights an improved satisfaction of public transport passengers as well as an increased awareness in Sustainable Urban Development Goals. The conclusions of the article drive in the direction that the proposed Sustainable Urban Development Card is an innovative 
approach to monitoring and analyzing low carbon energy public transport and contributes to the aim of zero local emission which is one of the aims of energy communities.

The article [2] by Aleksandra Lewandowska et al. analyses and assesses the level at which renewable energy facilities are being implemented or developed in the urban space of cities in Poland as a pillar of the implementation of the smart city concept. Thanks to a multistage research procedure the authors stated that renewable energy installations already exist in many cities in Poland and are highly increasingly becoming important features in urban areas. Concerning renewable energy installation the research study demonstrates that the most popular is photovoltaic in buildings or as autonomous power systems. Among these small-scale RES installations are spreading fast, meanwhile largescale ones are the result of the modernization of municipal sewage treatment plants, municipal heat and power plants and waste processing sites, where biogas and biomass are used in energy production. The authors conclusions are that identified place-based facilities prove that the smart city idea is increasing in popularity in Polish cities and it will represent an opportunity for cities, including post-socialist ones, to create a modern, functional, and environmentally friendly city (a smart city), and thus to build international market competitiveness.

Contributions [3] proposed by Nienke Maas et al. refers to energy flexibility aspects of Positive Energy Districts, addressing implementation conditions for energy flexibility technologies that facilitate cities to engender the expected impact and ensure replication and mainstreaming. The article capitalizes on the experience of EU H2020 Smart Cities and Communities project POCITYF, starting from the EU H2020 RUGGEDISED innovation and implementation framework for smart city technology, knowing that this framework is not concentrated on energy flexibility technologies alone. Thus in this paper the RUGGEDISED framework has been applied as a starting point to evaluate the implementation condition of energy flexibility solutions within the POCITYF project. Main findings rely on the area of services, legal framework and end users involvement.

The development of city-driven urban laboratories is considered a priority for setting up and replication of Positive Energy Districts in the article [4] by Silvia Soutullo et al. which refers to EERA Joint Programme on Smart Cities activity module 2. This strategic module assesses the development of city-driven Positive Energy Districts Laboratories (PED Lab). One of the objectives of EERA JP on SC module 2 is to identify research testing platforms (provided by members of EERA JP on SC) across countries in Europe that can be used for developing and testing integrated solutions and should work as drivers for local communities, districts, and cities. Once the information of the infrastructures submitted by the members of the EERA JP SC has been compiled, statistical studies have been performed to identify the main characteristics of these 16 facilities.

Sobah Abbas Petersen and all. [5] describe Smiling Earth, a mobile app to increase citizens' awareness about their own carbon footprint, by integrating energy and transportrelated data. The article explores the ways in which ICT could help raise awareness and educate and motivate citizens about their actions and consequences on the environment. The value of the Smiling Earth for individuals, cities, and communities are presented in the conclusion in terms of benefits to individuals, cities, and neighborhoods and benefits to citizens and communities of people, as well as the role of technologies from the different perspectives of an individual, a community or a city.

In [6], Dorota Chwieduk et al. evaluate the possible transition routes from the existing centralized energy systems in Polish cities to modern low emission distributed energy systems based on locally available energy sources, mainly solar energy. The evaluation of these possibilities is based first on the presentation of the current structure of energy grids and heating networks in Polish cities, then a basic review of energy consumption in the building sector is given with the emphasis on residential buildings. The paper deals with evaluation of the effectiveness of operation of central district heating systems and heat distribution systems, predicts the improvement in the effectiveness of the energy 
production, distribution and use, and analyses the possible integration of existing systems with distributed energy sources.

A new digital Geographic Information System (GIS) platform developed to quantify the energy savings obtained through the implementation of refurbishment measures in residential buildings, including solar thermal collectors and geothermal technologies, and assuming the postal district as the representative unit for the territory is presented in [7] by Emanuela Giancola et al. The new developed GIS platform based on the interaction of different technologies and available resources is a step forward in the field of built environment towards smart energy communities, supporting the low carbon energy transition. The article highlights the GIS methodology which has been applied to the Asturian region in Spain, qualified as a region in energy transition. The obtained results point to great energy mitigation potentials justifying the need for public authorities to develop policies aimed at reducing the energy demand of buildings, especially the heating loads. The generated maps could be helpful for retrofitting considerations for existing housing stock in the Principality of Asturias, a key action that is completed in combination with the use of solar thermal energy and geothermal resources towards sustainable development.

Silvia Bossi et al., in [8], proposes a solid understanding and consideration based on analysis of cities' strategies, experiences and project features which are the basis of developing and designing the PED program. JPI Urban Europe has been collecting information on projects towards sustainable urbanization and the energy transition across Europe. The collected cases are summarized in a PED Booklet whose update was recently published on the JPI Urban Europe website. Results presented in this paper provide insights from the analysis of 61 projects in Europe and offer recommendations for future PED developments. There is a broad variety of projects addressing energy transition. While only 29 of 61 projects are planning to implement PEDs, all of them provide valuable approaches and strategies regarding actions towards the energy transition in the urban context. Most of the projects classified as Towards PEDs seem to include the possibility to develop into PEDs in a further step. However, actual feasibility of many project designs is not yet accessible since a large share of the projects listed are in planning or early implementation stages, respectively. The PED Reference Framework with its focus on energy functions and overall sustainability goals provides an open framework; he results of the comparison between PED projects and Towards PEDs projects indicate that differences between the two groups are not categorical and the main issues and challenges of project implementation are similar. This, therefore, supports the assumption that projects with no self-declared PED ambition may be further developed to achieve PED status according to the PED Reference Framework. A further operationalization of the PED Reference Framework [5], which is currently under development, aims at a common PED definition that includes local differences and diverse approaches.

Conflicts of Interest: The author declares no conflict of interest.

\section{References}

1. Maestosi, P.C.; Andreucci, M.B.; Civiero, P. Sustainable Urban Areas for 2030 in a post-Covid-19 Scenario: Focus on innovative research and funding frameworks to boost transition towards 100 Positive Energy Districts and 100 Climate-Neutral Cities. Energies 2021, 14, 216. [CrossRef]

2. Lewandowska, A.; Chodkowska-Miszczuk, J.; Rogatka, K.; Starczewski, T. Smart energy in a smart city: Utopia or reality? Evidence from Poland. Energies 2020, 13, 5795. [CrossRef]

3. Maas, N.; Georgiadou, V.; Roelofs, S.; Lopes, R.A.; Pronto, A.; Martins, J. Implementation Framework for Energy Flexibility Technologies in Alkmaar and Évora. Energies 2020, 13, 5811. [CrossRef]

4. Soutullo, S.; Aelenei, L.; Nielsen, P.S.; Ferrer, J.A.; GonÇalves, H. Testing platforms as drivers for positive energy living laboratories. Energies 2020, 13, 5621. [CrossRef]

5. Petersen, S.A.; Petersen, I.; Ahcin, P. Smiling Earth-Raising Awareness among Citizens' for Behaviour Change to Reduce Carbon Footprint. Energies 2020, 13, 5932. [CrossRef] 
6. Chwieduk, D.; Bujalski, W.; Chwieduk, B. Possibilities of transition from centralised energy systems to distributed energy sources in large Polish cities. Energies 2020, 13, 6007. [CrossRef]

7. Soutullo, S.; Giancola, E.; Sánchez, M.N.; Ferrer, J.A.; García, D.; Súarez, M.J.; Prieto, J.I.; Antuña-Yudego, E.; Carús, J.L.; Fernández, M.Á.; et al. Methodology for quantifying the energy saving potentials combining building retrofitting, solar thermal energy and geothermal resources. Energies 2020, 13, 5970. [CrossRef]

8. Bossi, S.; Gollner, C.; Theierling, S. Towards 100 Positive Energy Districts in Europe: 3 preliminary data analysis of 61 European cases. Energies 2020, 13, 6083. [CrossRef]

9. Patalas-Maliszewska, J.; Łosyk, H. Analysis of the Development and Parameters of a Public Transport System which uses Low-carbon Energy-the Evidence from Poland. Energies 2020, 13, 5779. [CrossRef] 